\title{
The Effectiveness of Drinking and Driving Policies for Different Alcohol-Related Fatalities: A Quantile Regression Analysis
}

\author{
Yung-Hsiang Ying ${ }^{1}$, Chin-Chih $\mathrm{Wu}^{2, *}$ and Koyin Chang ${ }^{3, *}$
}

1 College of Management, National Taiwan Normal University, Taipei, 106, Taiwan; E-Mail: yying@ntnu.edu.tw

2 Institute of China and Asia-Pacific Studies, National Sun Yat-sen University, 70 Lienhai Rd., Kaohsiung 804, Taiwan

3 Department of Healthcare Information and Management, Ming Chuan University, 250 Chung-Shan N. Rd., Taipei 111, Taiwan

* Authors to whom correspondence should be addressed;

E-Mails: strawberry0620@gmail.com (C.-C.W.); koyin@kchang.net (K.C.); Tel.: +886-7-525-2000 (C.-C.W.), +886-3-350-7001 (K.C.); Fax: 886-3-359-3880 (K.C.).

Received: 17 July 2013; in revised form: 5 September 2013 / Accepted: 13 September 2013 / Published: 27 September 2013

\begin{abstract}
To understand the impact of drinking and driving laws on drinking and driving fatality rates, this study explored the different effects these laws have on areas with varying severity rates for drinking and driving. Unlike previous studies, this study employed quantile regression analysis. Empirical results showed that policies based on local conditions must be used to effectively reduce drinking and driving fatality rates; that is, different measures should be adopted to target the specific conditions in various regions. For areas with low fatality rates (low quantiles), people's habits and attitudes toward alcohol should be emphasized instead of transportation safety laws because "preemptive regulations" are more effective. For areas with high fatality rates (or high quantiles), "ex-post regulations" are more effective, and impact these areas approximately $0.01 \%$ to $0.05 \%$ more than they do areas with low fatality rates.
\end{abstract}

Keywords: quantile regression analysis; alcohol-related traffic fatalities; policies 


\section{Introduction}

Driving under the influence of alcohol has long been a severe social problem in the United States. In 2009, a study by the National Highway Traffic Safety Administration (NHTSA) indicated that approximately 30 people died in alcohol-related collisions per day (approximately 11,000 deaths per year); that is, one person dies in an alcohol-related collision every $48 \mathrm{~min}$. Additionally, this horrifying figure was the result of already improved traffic safety conditions (the data provided by the NHTSA showed that in approximately 1982, nearly 30,000 people died in alcohol-related collisions in the U.S. per year, which accounted for $60 \%$ of the overall traffic crashes. Today that percentage has dropped to 38\%). In 1980, Mothers Against Drunk Driving (MADD) was founded in the U.S., dedicating itself to urging state and federal governments to enact a series of drinking and driving policies that significantly reduced alcohol-related fatalities in the U.S. Since then, government officials and scholars have conducted numerous investigations and studies on the effectiveness of drinking and driving policies in reducing alcohol-related fatalities.

The data used in the studies on drunk driving consist of three categories: Cross-sectional data (e.g., Beck et al., [1]; Paschall, [2]; Phelps, [3]), time-series data (e.g., Whetten-Goldstein et al.,[4]; Villaveces et al., [5]), and panel data (e.g., Chang et al., [6]; Lovenheim and Slemrod, [7]; Hingson et al., [8]; Ruhm, [9]; Males, [10]; Cook \& Tauchen, [11]; Saffer and Grossman, [12]). Two estimation methods were used in these traditional econometric studies: (1) the ordinary least square (OLS) method that estimates the conditional mean function of dependent variables; and (2) the least absolute deviation (LAD) method that estimates the conditional median function of dependent variables. These two estimation methods emphasize the central tendency distribution of dependent variables and they both address the data at a macro or comprehensive level instead of examining individual quantiles. However, an observation of the alcohol-related fatality data show that we must study the development tendency of the alcohol-related fatalities of individual quantiles in addition to the central tendency development of alcohol-related fatalities. The reasons are as follows:

\subsection{High Consistency of the U.S. Alcohol-Related Fatalities}

Figure 1 shows that although U.S. alcohol-related fatalities have declined significantly, the states with high rates of alcohol-related fatalities in 1982 had maintained comparatively high levels in 2009 (e.g., CA, TX, and FL); the opposite situation was also true (e.g., in UT, VT, and RI). Based on this phenomenon, we suspect that drinking and driving policies that showed mean effectiveness had different effects for varying quantiles or alcohol-related fatality rates, preventing the values for states in Quadrant 3 (i.e., the states that maintained high rates of alcohol-related fatalities) from moving toward Quadrant 1 (i.e., the states that had shown high alcohol-related fatalities transformed into states with low alcohol-related fatalities).

\subsection{Regional Difference in United States Alcohol-Related Fatalities}

Figure 2 shows that the states with relatively high alcohol-related fatalities are situated in the west and the south, whereas the states with relatively low alcohol-related fatalities are situated in the northeast, indicating that U.S. alcohol-related fatality are regional. Chang et al. [6] indicated that the 
drinking and driving policies in different regions had varying effects (In Chang et al. [6], the U.S. was divided into Far West, Great Lakes, Mid East, New England, Plains, Rocky Mts., Southeast, and Southwest). We concluded that different drinking and driving policies had different effects depending on the level of alcohol-related fatalities.

Figure 1. Alcohol-related fatalities in 2009 (horizontal axis) and 1982 (vertical axis).

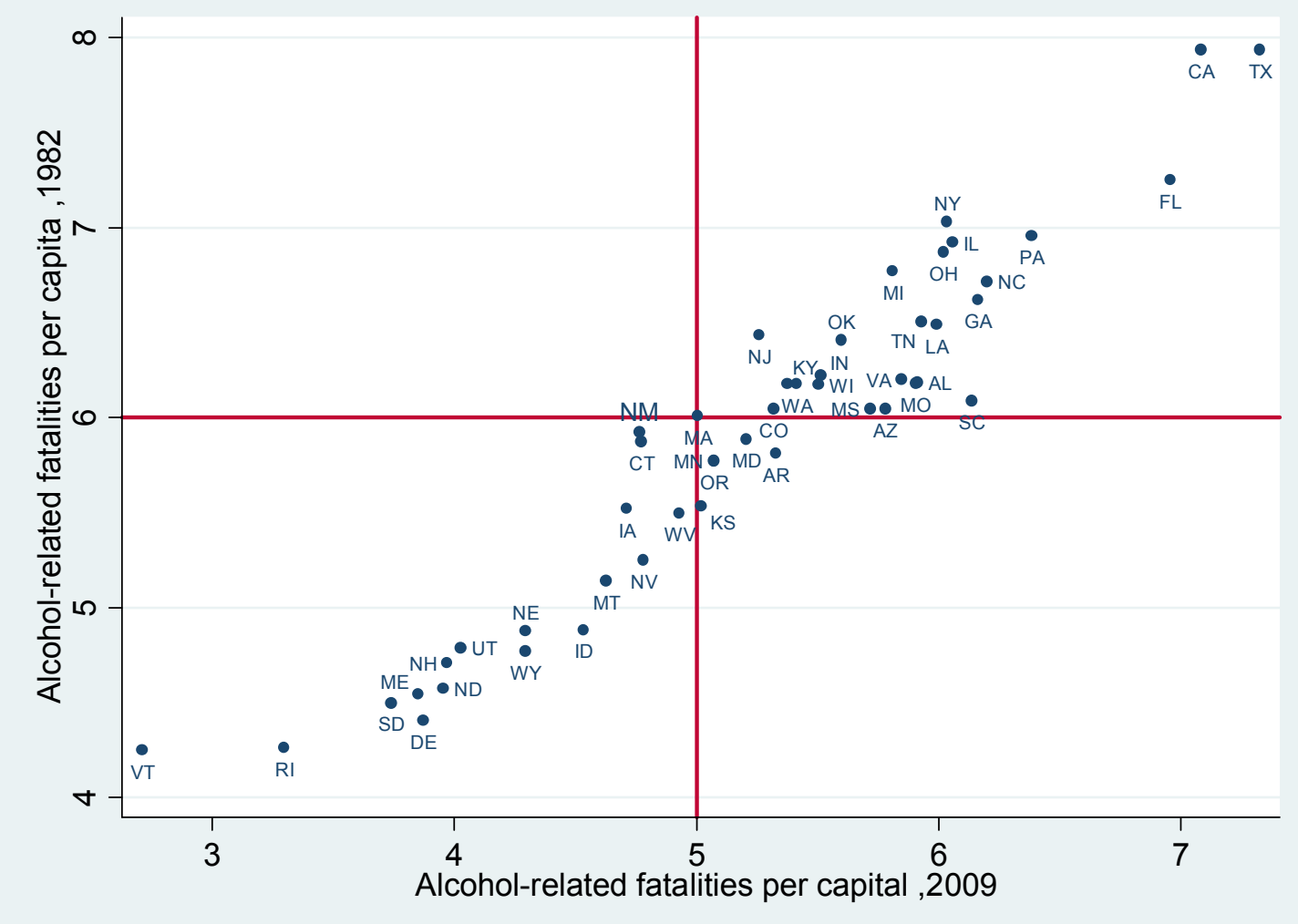

Figure 2. Fatalities as a percentage of total fatalities in crashes involving at least one driver with a $\mathrm{BAC}=0.08+, 2006$ (Source: NHTSA).

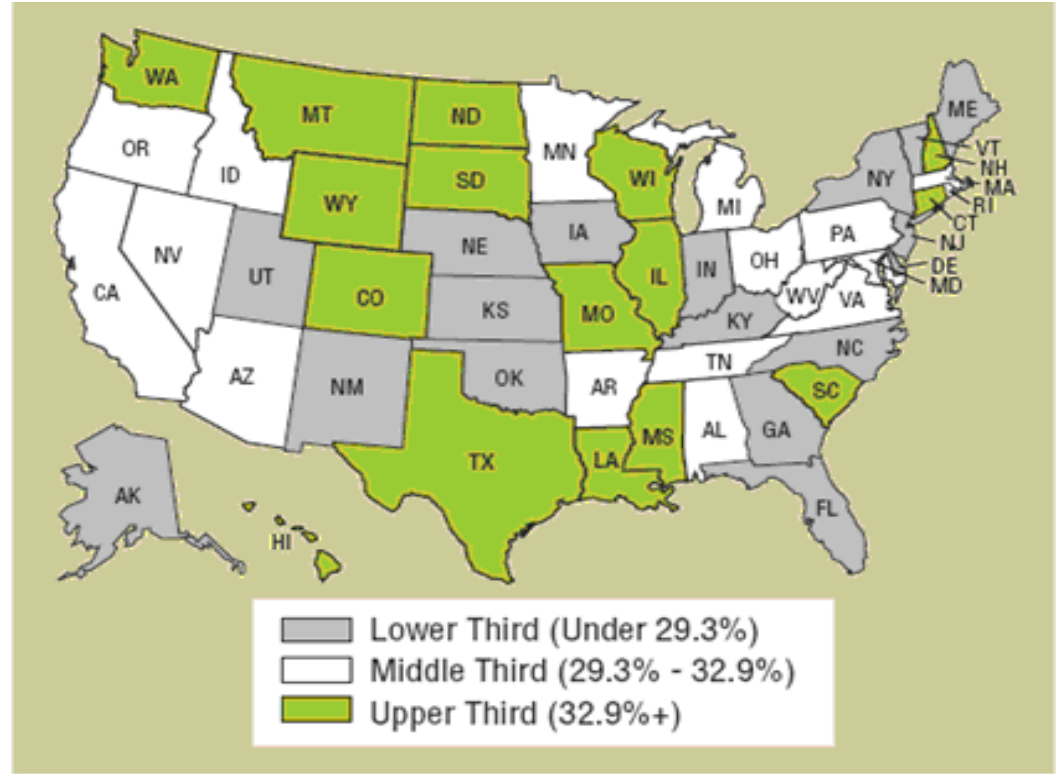


This finding provided strong motivation to examine the effectiveness of drinking and driving policies under different alcohol-related fatality rates. To effectively discuss the effects of various drinking and driving policies on alcohol-related fatalities in different quantiles, we used the quantile regression method proposed by Koenker and Bassett [13] for estimation. The simple concept of the advantage of quantile regression, relative to the ordinary least squares regression, is that the quantile regression estimates are more robust against outliers in the response measurements [14]. Other advantages of the quantile regression method include that it makes no distribution assumptions on the population; it supplements the insufficiency of the traditional regression methods, which focuses only on the mean value of alcohol-related fatalities to estimate and interpret drinking and driving policy parameters; and finally, in our study, it specifically identifies the differing effect levels of drinking and driving policies on alcohol-related fatalities in different quantiles. Thus, we believe that applying QR model has advantages over the traditional method.

The structure of this study is as follows: research motivation and objectives are introduced in Section 1. In Section 2, we provide background information for the alcohol control- and road safetyrelated policies and review empirical studies on drunk driving. In Section 3, we explain the methodology and the quantile regression model. In Section 4, we provide the results of the empirical study; we follow the steps provided in the research methodology to implement empirical research and introduce, interpret, and analyze the results from the conducted empirical study. Finally, in Section 5, we present a conclusion in which the empirical results are integrated and conclusions and suggestions for future studies are provided.

\section{Background and Literature Review}

The establishment of MADD was significant in the history of U.S. drinking and driving policies. Although the first U.S. law against drunk driving was passed in New York in 1910, other state governments and the federal governments did not pass such laws until MADD was founded in 1980, when the organization launched a wave of lobbying and campaigns. This led to a gradual trend toward more complete U.S. drinking and driving laws and policies.

\subsection{Minimum Legal Drinking Age}

In 1933, after the U.S. prohibition of the manufacture and sale of alcoholic beverages was lifted, the states began to set minimum legal drinking ages (MLDA), most of which were 21 years of age. By the early 1970s, most states had lowered their MLDAs to between 18 and 20 years of age, resulting in numerous discussions and studies. Most of these studies showed that the rise and decline of teenage car crash fatalities were related to MLDA [15]. Therefore, in 1984, the U.S. Congress enacted legislation that set the MLDA, stipulating that states that failed to raise their MLDA to 21 would lose a portion of their federal highway construction funding. By 1988, all states had raised their MLDA to 21. MLDA has remained one of the most researched alcohol prevention policies. The studies by Saffer and Grossman [12], Wilkinson [16], Wagenaar [17], Dee [18], Voas et al. [19] and Fell et al. [20] indicated that raised MLDAs effectively reduced alcohol-related traffic collisions. 


\subsection{Blood Alcohol Concentration}

In 1939, the State of Indiana first enacted a blood alcohol concentration (BAC) limit of less than 0.15. In 1983, Oregon and Utah lowered their BAC from 0.1 to 0.08. In a report to Congress in 1991, the NHTSA proposed lowering the BAC to 0.08, and the law limiting BAC was passed by Congress in the same year. In 1998, Congress established the National Mobile Incentive Grant Scheme to strictly enforce the BAC. In 2000, Congress encouraged states to implement BAC restrictions, stipulating that the states that failed to lower their BAC to 0.08 would lose a portion of their federal highway construction funding. By 2004, all states enacted a BAC limit of 0.08 .

Hingson et al. [21], Fell and Voas [22], Tippetts et al. [23], Kaplan and Prato [24], and Wagenaar et al. [25] showed that lowering the BAC from 0.10 to 0.08 reduced alcohol-related fatalities by $5 \%$ to $16 \%$, saving approximately 400 lives per year.

\subsection{Zero Tolerance}

Zero tolerance was a combination of MLDA and BAC. This act stipulated that drivers under the age of 21 should not demonstrate a BAC exceeding $0.02 \%$. Maryland first passed the Zero Tolerance Law in 1990. In 1995, to encourage other states to enact the Zero Tolerance Law, Congress stipulated under the National Highway Systems Designation Act (NHSDA) that the states that failed to enact the Zero Tolerance Law would lose a portion of their federal highway construction funding. By 1998, all states had implemented the Zero Tolerance Law. Zwerling and Jones [26], Wagenaar et al. [27], Voas et al. [28], Carpenter et al. [29], and Liang and Huang [30] showed that the Zero Tolerance Act reduced alcoholrelated fatalities by $4 \%$ to $24 \%$.

\subsection{Open Container Laws}

The Open Container Laws regarding drinking and driving stipulated that the drivers would be fined if open containers of alcoholic beverages were found in the cabins of their vehicles. Because this was an interstate law instead of a federal law, the states had the right to decide whether they issued the law and they could also adjust the contents of this law. In 1988, to encourage states to pass the Open Contain Laws, Congress stipulated that states that failed to implement the Open Container Laws would lose a portion of their federal highway construction funding. Currently, only 43 states have enacted this law. Eisenberg [31] and Benson et al. [3] showed that this law had a negative correlation with alcoholrelated fatalities.

\subsection{Driving Under the Influence}

The Driving Under the Influence (DUI) Law was constructed in the framework of BAC limits. The "Administrative License Revocation" (ALR) and DUI fine were articles of the DUI Law. Under the ALR law, licenses are immediately revoked whenever a driver either: (1) refuses to submit to BAC testing; or (2) submits to testing with results indicating a BAC over the legal limit of $0.08 \%$ (by 2011, 42 states had implemented the ALR, leaving eight states not yet adopting the law: Kentucky, Michigan, Montana, New Jersey, Pennsylvania, Rhode Island, South Dakota, and Tennessee). Ruhm [9], Voas et al. [32], and Wagenaar and Maldonado-Molina [33] indicated that ALR had significant effects 
on reducing alcohol-related fatalities. The DUI fines varied among states, with the lowest fines for first-time offenders ranging from US\$150 in Wisconsin to US\$2,000 in Texas. The results of studies on DUI fines differed. Chaloupka et al. [34] and Wagenaar et al. [25] indicated that DUI fins had significant effects on reducing alcohol-related fatalities, whereas Sloan et al. [35] sowed that DUI fines had no significant effects on reducing alcohol-related fatalities, and Young and Likens [36] found a positive correlation between DUI fines and alcohol-related fatalities.

Based on the definition proposed by Becker and Posner [37], we classifed these drinking and driving policies into two categories: preventive and ex-postregulations. Preventive regulations were enacted to prevent drinking and driving, including the Beer tax, MLDA, and Open Container Laws, whereas ex-post regulations were enacted to penalize drivers under the influence of alcohol, including the 0.08 BAC limit, ALR, the Safety Belt Law, the Zero Tolerance Law, speed limits, and DUI fines. Although some laws such as the beer tax, speed limits, and the Safety Belt Law were not intended to reduce alcohol-related collisions, numerous studies have observed that these laws had direct and significant effects on alcohol-related fatalities. Specifically, the effects of the beer tax on alcohol-related fatalities were widely examined. For example, the empirical results of Chaloupka and Wechsler [38], Phelps [39], Kenkel [40], Saffer and Grossman [12], and Mann et al. [41] showed a significant negative correlation between the beer tax and alcohol-related fatalities, whereas the empirical results of Sloan and Githens [42], Dee [18], Mast et al. [43], and Young and Likens [36] indicated that the relationship between the beer tax and alcohol-related fatalities was neither significant nor necessarily negatively correlated.

\section{Research Model and Methodology}

\subsection{Panel Data Quantile Regression Model}

The quantile regression (QR) analysis was proposed in Koenker and Bassett [13] as an expansion of the least absolute deviation (LAD). QR can be used to detail the performance of explanatory variables under the influence of conditional medians. Additionally, it can be expanded to analyze the performance of variables under the influence of different conditional quantiles.

Based on the descriptions in the study by Koenker \& Bassett (1978), we established a random variable cumulative distribution function, as shown in Equation (1):

$$
\operatorname{Py}\left(y_{i t}<y \mid x_{i t}\right)=F\left(y-x_{i t} \beta \mid x_{i t}\right)=\tau, \tau \in(0,1)
$$

where $y_{i t}$ represents the dependent explanatory variable vector, and $x_{i t}$ is the independent explanatory variable vector. $\beta$ is the regression coefficient vector obtained through estimation satisfying (1) and varies according to different quantiles $\tau$. Therefore, $\beta(\tau)$ represents the regression coefficient vector under the influence of the $\tau$ th quartile.

We simplified (1) into a basic panel data quantile regression model, as shown in Equation (1.1). (Equation (1) can be simplified into the conditional quantile form: $Q_{y i t}\left(\tau \mid x_{i t}\right)=\alpha_{i}+x_{i t}^{\prime} \beta(\tau)$, where $Q_{y i t}\left(\tau \mid x_{i t}\right)$ represents the conditional quantile of yit under a set, xit assuming $\left.Q_{y i t}\left(\varepsilon_{i t}(\tau) \mid x_{i t}\right)=0\right)$ :

$$
y_{i t}=\alpha_{i}+x_{i t}^{\prime} \beta(\tau)+\varepsilon_{i t}(\tau)
$$


where $\varepsilon_{i t}(\tau)$ represents the random error under quantile $\tau$, and $\alpha_{i}$ represents the regional fixed effects that are unaffected by quantile $(\tau)$ and capture unobserved time-invariant heterogeneity between regions [14]. Also included is the state-specific time fixed effect to guarantee that the results are not due to the trend of fatalities caused by drunk driving [9]. The conditional expectation value in traditional panel data analysis is a linear operator; thus, within group estimation is used to eliminate the $\alpha_{i}$ in the model and prevent biased estimation. However, the conditional quantile in the QR analysis is not a linear estimator, and within group estimation cannot be used to eliminate the fixed effects. Therefore, Koenker [14] introduced an objective function with penalty terms to eliminate the fixed effects, as shown in Equation (2):

$$
\min _{\alpha_{i}, \beta(\tau j)} \sum_{j=1}^{J} \sum_{t=1}^{T} \sum_{i=1}^{n} \omega_{j} \rho_{\tau j}\left(y_{i t}-\alpha_{i}-x_{i t}^{\prime} \beta(\tau j)\right)+\lambda \sum_{i=1}^{n}\left|\alpha_{i}\right|
$$

where $\sum_{i=1}^{n}\left|\alpha_{i}\right|$ is the penalty. When $\lambda=0$, it represents the traditional fixed effects, and when $\lambda>0$, it represents the fixed effects with a penalty. Thus, the panel data QR estimated value $\hat{\beta}(\tau)$ under fixed effects can be obtained [14] verified that $\hat{\beta}(\tau)$ was the consistency estimation equation for $\beta(\tau)$ and its progressive distribution was normal distribution] representing the marginal effects of different quantile explanatory variables on the explained variables when other explanatory variables $x_{i}$ were controlled. In other words, when $x_{i}$ changes by one unit, the quantile $\tau$ value of the explained variable changes by $\hat{\beta}(\tau)$ units.

Based on the suggestions in Lamarche [44], we used the bootstrap method for sampling estimation. In this method, the re-sampling of samples was used to simulate the population distribution. We also relaxed the assumption limit that requires the conditional distribution of the errors to be homoscedastic [45]. Therefore, a variance matrix estimation equation with consistency was obtained, as shown in Equation (3).

$$
\widehat{\operatorname{Var}}(\hat{\beta}(\tau))=\frac{1}{B-1} \sum_{b=1}^{B}\left(\widehat{\beta_{b}^{*}}(\tau)-\overline{\widehat{\beta}^{*}}(\tau)\right)\left(\widehat{\beta_{b}^{*}}(\tau)-\widehat{\widehat{\beta^{*}}}(\tau)\right)^{\prime}
$$

where $\widehat{\beta_{b}^{*}}(\tau)=B^{-1} \sum_{b=1}^{B} \widehat{\beta_{b}^{*}}(\tau)$.

The QR model can describe the performances of different quantile conditional distributions and therefore can more fully describe the characteristics of samples. This is different from the OLS model describes only the mean marginal effects of the explanatory variables on the explained variables.

\subsection{Empirical Model}

Because this model was comparatively suitable, we used the panel data QR model to explore and verify whether changes in the effectiveness of drinking and driving policies occur with varying levels of alcohol-related fatalities. Based on the framework in Koenker [14], we established an empirical model for panel data QR, as shown in Equation (4):

$$
\operatorname{ARFR}_{\mathrm{it}}=\alpha_{i}+L_{i t}^{\prime} \beta(\tau)+\operatorname{CONTROL}_{i t}^{\prime} \beta(\tau)+\varepsilon_{i t}(\tau)
$$

where $\varepsilon_{i t}(\tau)$ and $\alpha_{i}$ are explained in the paragraph following Equation (1.1). Annual data from the 48 contiguous states for the years 1982 to 2009 are employed. $A R F R_{i t}$ represents the alcohol-related fatalities per 100,000 population (according to Chang et al. [6], a lowered ARFR indicates that the 
traffic conditions in a state were undergoing improvement, that is, improved traffic conditions were beneficial to reducing alcohol-related fatalities) obtained from the Fatal Accident Reporting System (FARS) of the NHTSA. CONTROL $L_{i t}$ represents geo-economic factors, such as population density (Pop. density ${ }_{i t}$ ), income (Income ${ }_{i t}$ ), unemployment rates (Unemp. rate ${ }_{i t}$ ), teenage/young driver ratio (Under $24_{i t}$ ), and U.S. administrative districts. $L_{i t}$ represents the nine drinking and driving policies selected for this discussion: The beer tax $\left(\right.$ Beer tax $\left._{i t}\right), \operatorname{MLDA}\left(\mathrm{MLDA}_{i t}\right), \mathrm{BAC}\left(\mathrm{Bac}_{i t}\right), \mathrm{ALR}\left(\mathrm{ALR}_{i t}\right)$, the Safety Belt Law $\left(\right.$ Belt $_{i t}$ ), the Zero Tolerance Law (Zero tolerance ${ }_{i t}$ ), Open Container Laws (Open container ${ }_{i t}$ ), the speed limit (Speed limit ${ }_{i t}$ ), and DUI fines (DUI fine ${ }_{i t}$ ) (these policies have been passed and implemented in all states at different times). These policies were set as the dummy variables in this model except for the beer tax. If states had adopted a policy, it was marked as 1 ; if they had not, it was marked as 0 . Please refer to Table 1 for the details of the variables.

Table 1. Variable definition and statistics.

\begin{tabular}{|c|c|c|}
\hline Variable & Definition, mean, SD & Source \\
\hline ARFR & $\begin{array}{l}\text { Alcohol-related deaths }(\mathrm{BAC} 0.1+\text { ) resulting from motor vehicle crashes per } \\
100,000 \text { population, mean }=8.23, \mathrm{SD}=3.67\end{array}$ & NHTSA \\
\hline Income & $\begin{array}{l}\text { Per capita personal income divided by CPI, expressed in thousands of dollars, } \\
\text { mean }=24.06, \mathrm{SD}=9.32\end{array}$ & $\begin{array}{l}\text { Statistical Abstract } \\
\text { of the U.S. }\end{array}$ \\
\hline Unemp. rate & State unemployment rate, mean $=5.76, \mathrm{SD}=2.05$ & $\begin{array}{l}\text { Bureau of Labor } \\
\text { Statistics }\end{array}$ \\
\hline Pop. density & Population per square mile of land area, mean $=4.42, \mathrm{SD}=1.30$ & $\begin{array}{l}\text { Statistical Abstract } \\
\text { of the U.S. }\end{array}$ \\
\hline Under24 & $\begin{array}{l}\text { Fraction of licensed drivers age } 16 \text { to } 24 \text { years (Number of licensed drivers age } \\
16 \text { to } 24 \text { years as a fraction of total licensed drivers of all ages), } \\
\text { mean }=0.16, \mathrm{SD}=0.14\end{array}$ & Highway Statistics \\
\hline Beer tax & $\begin{array}{l}\text { Sum of Federal and State excise taxes on a case of } 24 \times 12 \mathrm{oz} \text { cans of beer } \\
\text { divided by CPI }(1982=1) \text {, mean }=0.4921, \mathrm{SD}=0.04\end{array}$ & $\begin{array}{l}\text { Brewers'Almanac, } \\
\text { U.S. Brewers } \\
\text { Association and } \\
\text { Significant } \\
\text { Features of Fiscal } \\
\text { Federalism }\end{array}$ \\
\hline Belt & $\begin{array}{l}\text { Dichotomous variable that is coded as } 1 \text { if the state had passed the safety belt } \\
\text { law, mean }=0.76, \mathrm{SD}=0.43\end{array}$ & NHTSA \\
\hline ALR & $\begin{array}{l}\text { Dichotomous variable that is coded as } 1 \text { if the state suspends the drivers' licenses } \\
\text { of individuals who are arrested for driving while intoxicated (DWI), } \\
\text { mean }=0.64, \mathrm{SD}=0.48\end{array}$ & NHTSA \\
\hline Bac08 & $\begin{array}{l}\text { Dichotomous variable that was coded as } 1 \text { if the state considers it an offense to } \\
\text { operate a motor vehicle with a BAC at or above } 0.08 \%, \text { mean }=0.38, \mathrm{SD}=0.49\end{array}$ & NHTSA \\
\hline $\begin{array}{l}\text { Zero } \\
\text { tolerance }\end{array}$ & $\begin{array}{l}\text { Dichotomous variable that was coded as } 1 \text { if the state made it illegal per se for } \\
\text { persons under the age of } 21 \text { to drive with any measurable amount of alcohol in } \\
\text { their blood, mean }=0.53, \mathrm{SD}=0.49\end{array}$ & NHTSA \\
\hline MLDA & $\begin{array}{l}\text { Minimum legal drinking age in years for the purchase and consumption of beer, } \\
\text { alcoholic content more than } 3.2 \%, \text { mean }=0.91, \mathrm{SD}=0.29\end{array}$ & NHTSA \\
\hline Speed limit & $\begin{array}{l}\text { Dichotomous variable that was coded as } 1 \text { if the state mandated a maximum } \\
\text { speed limit of } 70 \mathrm{mph} \text { for its rural state highways, mean }=0.91, \mathrm{SD}=0.45\end{array}$ & $\begin{array}{l}\text { Insurance Institute } \\
\text { for Highway Safety }\end{array}$ \\
\hline $\begin{array}{l}\text { Open } \\
\text { container }\end{array}$ & $\begin{array}{l}\text { Dichotomous variable that was coded as } 1 \text { if the state prohibited possessing } \\
\text { and/or drinking from an open container of alcohol in moving motor vehicles in } \\
\text { certain areas, mean }=0.25, \mathrm{SD}=0.43\end{array}$ & $\begin{array}{l}\text { Alcohol policy } \\
\text { information system } \\
\text { (APIS) }\end{array}$ \\
\hline
\end{tabular}


Table 1. Cont.

\begin{tabular}{lll}
\hline Variable & Definition, mean, SD & Source \\
\hline \multirow{2}{*}{ DUI fine } & $\begin{array}{l}\text { Dichotomous variable that was coded as 1 if the state passed DUI fine laws, } \\
\text { mean }=0.53, \mathrm{SD}=0.50\end{array}$ & $\begin{array}{l}\text { Each State } \\
\text { Government }\end{array}$ \\
\hline Northwest & States include CT, MA, ME, NH, NY, PA, RI, VT & U.S. Bureau of \\
\hline Midwest & States include IA, IL, IN, KS, MN, MO, MI, ND, NE, OH, SD, WI & Economic Analysis \\
\hline West & States include AZ, CA, CO, ID, MT, NM, NV, OR, UT, WA, WY & \\
\hline \multirow{2}{*}{ South } & States include AL, AR DC, DE, FL, GA, KY, LA, MD, MS, NC, OK, SC, TN, & \\
\hline
\end{tabular}

Note: 1. NHTSA represents National Highway Traffic Safety Administration; 2. The abbreviation of each state in the USA are explained in Table A1.

\section{Results}

To clearly explain the estimation results of QR with different quantiles, we use the definition of QR $\hat{\beta}(\tau)$ to classify alcohol-related fatalities into three types based on their quantiles: (1) $\tau=0.25$ represented that the area had a low rate of alcohol-related fatalities; (2) $\tau=0.5$ represented that the area had a medium rate of alcohol-related fatalities; and (3) $\tau=0.75$ represented that the area had a high rate of alcohol-related fatalities. We then conducted empirical analyses based on Equation (4) to discuss the effects of drinking and driving policies and other control variables on alcohol-related fatalities.

Table 2 shows four characteristics: (1) In the areas with low rates of alcohol-related fatalities, increases in unemployment rates and the number of young drivers (licensed drivers aged between 16 and 24 years of age) correlated with significant increases in alcohol-related fatalities. In these areas, preventive regulations (such as MLDA and the beer tax) were relatively more effective in reducing alcohol-related fatalities than ex-post regulations; (2) In areas with high rates of alcohol-related fatalities, socio-economic factors such as employment rate, and the number of young drivers had no significant effects on fatalities. In these areas, ex-post regulations (such as BAC limit (0.08) and ALR) correlated with reductions in fatalities at $1 \%$ significance level; (3) In terms of regional fixed effect, all coefficients of three regions are negative, indicating that the omitted region, South, had the highest alcohol-related fatalities rate. Since the second highest region was West, our results appear to support the original finding described in Figure 2; (4) The effects of preventive regulations declined as the rate of alcohol-related fatalities increased, whereas the opposite was observed for ex-post regulations. This indicates that in areas with high rates of alcohol-related fatalities, ex-post regulations were more effective than preventive regulations. The only ineffective traffic law in reducing alcohol-related fatalities in all quantiles is the speed limit. In the following section, we detail the effectiveness of various drinking and driving policies and other control variables in areas with high, medium, and low rates of alcohol-related fatalities.

\subsection{Areas with Low Alcohol-Related Fatalities}

Table 2 shows that all drinking and driving polices except for speed limit had significant effects on lowering rates of alcohol-related fatalities in these areas. Among all policies, the beer tax was the most effective in lowering fatalities. Assuming that other conditions remained constant, when the beer tax increased by $1 \%$, the rate of alcohol-related fatalities declined by $0.41 \%$. Additionally, zero tolerance, 
the Open Container Law, and BAC effectively reduced the rate of fatalities in these areas, showing decreases of $0.18 \%, 0.14 \%$, and $0.06 \%$, respectively.

Other economic and demographic variables, such as per capita income, unemployment rates, and the number of young drivers all had significant effects in these areas at 5\% level. Unemployment rates and the number of young drivers have a significant positive correlation with alcohol-related fatalities, that is, increases in unemployment rates and the proportion of young drivers caused an increase in fatalities. In particular, when the number of young drivers increased $1 \%$, the rate of fatalities increased $0.08 \%$ holding other conditions constant. Conversely, per capita income had a significant negative correlation with alcohol-related fatalities. Assuming that other conditions remained constant, when the per capita income increased $1 \%$, the alcohol-related fatalities declined $0.036 \%$.

Table 2. Panel data quantile regression analysis.

\begin{tabular}{lrlrlrl}
\hline Variable & \multicolumn{2}{c}{ 25 percentile } & \multicolumn{2}{c}{ 50 percentile } & \multicolumn{2}{c}{$\mathbf{7 5}$ percentile } \\
\hline (ARFR) & Coeff & $\boldsymbol{Z}$-value & Coeff & $Z$-value & Coeff & $Z$-value \\
\hline Income & -0.036 & $0.020 * *$ & -0.016 & $0.072 *$ & -0.026 & $0.018 * *$ \\
Unemp. rate & 0.031 & $0.000 * * *$ & 0.011 & $0.066 *$ & 0.004 & 0.548 \\
Pop. Density & -0.166 & $0.000 * * *$ & -0.165 & $0.000 * * *$ & -0.154 & $0.000 * * *$ \\
Under24 & 0.081 & $0.000 * * *$ & 0.042 & 0.236 & 0.006 & 0.882 \\
Beer tax & -0.413 & $0.000 * * *$ & -0.312 & $0.000 * * *$ & -0.252 & $0.031 * *$ \\
Belt & -0.051 & $0.041 * *$ & -0.064 & $0.004 * * *$ & -0.042 & $0.011 * *$ \\
ALR & -0.058 & $0.025 * *$ & -0.054 & $0.034 * *$ & -0.065 & $0.000 * * *$ \\
Bac08 & -0.066 & $0.002 * * *$ & -0.072 & $0.000 * * *$ & -0.101 & $0.000 * * *$ \\
Zero Tolerance & -0.184 & $0.000 * * *$ & -0.248 & $0.000 * * *$ & -0.283 & $0.000 * * *$ \\
MLDA & -0.012 & $0.006 * * *$ & -0.011 & $0.010 * *$ & -0.004 & $0.018 * *$ \\
Speed limit & 0.113 & $0.068 *$ & 0.129 & 0.072 & 0.137 & 0.074 \\
Open Container & -0.142 & $0.000 * * *$ & -0.193 & $0.000 * * *$ & -0.103 & $0.025 * *$ \\
DUI fine & -0.034 & $0.092 *$ & -0.006 & 0.332 & -0.042 & $0.033 * *$ \\
North West & -0.330 & $0.000 * * *$ & -0.321 & $0.000 * * *$ & -0.344 & $0.000 * * *$ \\
Midwest & -0.344 & $0.000 * * *$ & -0.328 & $0.000 * * *$ & -0.331 & $0.000 * * *$ \\
West & -0.263 & $0.000 * * *$ & -0.236 & $0.000 * * *$ & -0.158 & $0.000 * * *$ \\
Constant & 2.447 & $0.000 * * *$ & 2.633 & $0.000 * * *$ & 2.425 & $0.000 * * *$ \\
\hline Pseudo-R ${ }^{2}$ & 0.505 & & 0.571 & & 0.498 & \\
\cline { 1 - 3 } Obs. number & 1344 & & 1344 & & 1344 & \\
\hline
\end{tabular}

Notes: 1 . The 25, 50, and 75 percentiles represent the areas with 25 th, 50 th, and 75 th percentiles of the rate of alcohol-related fatality; 2. ARFR, Beer tax, income, unemployment rate, and population density are in natural logarithms; 3. The geographic area "South" is omitted for the comparison base; 4. ***, **, * represent significance levels of $1 \%, 5 \%$, and $10 \%$, respectively; 5 . State-specific time dummies were also included in the regressions while their coefficients are not reported to reduce paper length.

From these analyses, we observed that in the areas with low alcohol-related fatalities, in addition to the increased fatalities caused by economic pressure from unemployment and low per capita income [46], the effects of young drivers on increased alcohol-related fatalities should not be overlooked. In summary, in these areas, alcohol abuse and poor attitudes toward alcohol had a more severe effect on alcohol-related fatalities than poor traffic conditions [6]. Therefore, preventive regulations that are 
intented to prevent drunk driving were more effective and important than ex-post regulations that are intended to penalize drunk driving offenders.

\subsection{Areas with Medium Alcohol-Related Fatalities}

In the areas with medium rates of alcohol-related fatalities, the effects of the speed limit were insignificant, that is, the speed limit in these areas failed to effectively reduce rates of alcohol-related fatalities. Other drinking and driving policies had significant effects on the rates of alcohol-related fatalities in these areas. The beer tax was still the most effective in reducing rates of alcohol-related fatalities. Assuming that other conditions remained constant, when the beer tax increased by $1 \%$, fatalities declined by $0.31 \%$. Additionally, the zero tolerance, open container, and BAC regulations in these areas effectively reduced the rates of alcohol-related fatalities, by $0.25 \%, 0.19 \%$, and $0.07 \%$, respectively.

In these areas, the number of young drivers had no significant effects on alcohol-related fatalities, indicating that young drivers were not the major cause or focus of alcohol-related fatalities in these areas. Other economic and demographic variables (such as per capita income, unemployment rates, and population density) had significant effects on fatalities at $10 \%$ significance level. In particular, per capita income and population density had significant negative correlations with alcohol-related fatalities, that is, when per capita income or population density increased, fatalities declined by $0.016 \%$ and $0.165 \%$, respectively. Unemployment rates had a significant positive correlation with fatalities at $10 \%$ significance level. Assuming that other conditions remained constant, when unemployment rates increased by $1 \%$, fatalities increased by $0.011 \%$.

From these analyses we observed that in the areas with medium alcohol-related fatalities, traffic conditions should be improved and alcohol abuse and poor attitudes toward alcohol should be discouraged to reduce alcohol-related fatalities. In summary, preventive and ex-post regulations were both significant.

\subsection{Areas with High Alcohol-Related Fatalities}

Most of the included drinking and driving policies all had significant effects in the areas with high alcohol-related fatalities. In particular, the three most effective traffic laws for reducing fatalities were zero tolerance, open container, and BAC for reducing fatalities rates by $0.28 \%, 0.103 \%$, and $0.101 \%$, respectively. The only traffic law that showed insignificant result was speed limit. In these areas, fewer economic and demographic variables (only per capita income and population density) had significant effects on reducing alcohol-related fatalities, indicating that unemployment rates and the number of young drivers were not major causes of drunk driving in these areas. In summary, improving traffic conditions or creating safe traffic conditions is essential for reducing alcohol-related fatalities in these areas. Additionally, ex-post regulations such as zero tolerance and BAC were relatively more effective than preventive ones. 


\subsection{Comparisons across Quantiles}

To test whether all three quantiles were statistically different from each other, Chow tests were performed and presented in Table 3, which indicates that the QR results were significantly different at $5 \%$ level for each pair of QR comparison. For systemic comparisons between coefficients across quantiles, differences between coefficients for each variable were computed and the results are presented in Table 3. For the laws that are more effective in the areas with low alcohol-related fatalities, negative numbers appear in the columns of coefficient difference throughout the three pairs of comparison were obtained, which were MLDA and speed limit. Beer tax also worked more effectively in the areas with low alcohol-related fatalities. BAC and zero tolerance, on the other hand, are more effective in the areas with high alcohol-related fatalities. Thus, the areas with different conditions of alcohol-related fatalities should focus on different policies when enforcing the laws. In short, compared with areas that had low fatalities, the effects of preventive regulations for suppressing alcohol-related fatalities had declined in the areas with high fatalities, whereas the effects of ex-post regulations for suppressing fatality rates had increased in general. (The changes of the effects of preventive regulations are as follows: MLDA declined from $0.012 \%$ to $0.004 \%$, and the Open Container Law from $0.142 \%$ to $0.103 \%$. The changes of the effects of ex-post regulations are as follows: Zero Tolerance increased from $0.184 \%$ to $0.283 \%$, BAC $(0.08)$ increased from $0.066 \%$ to $0.101 \%$, ALR from $0.058 \%$ to $0.065 \%$, and DUI fines from $0.034 \%$ to $0.042 \%$.)

Table 3. Comparison between coefficients from different quantile regressions.

\begin{tabular}{|c|c|c|c|c|c|c|}
\hline \multicolumn{7}{|c|}{ Difference Between Coefficients } \\
\hline \multirow{2}{*}{$\begin{array}{l}\text { Variable } \\
\text { (ARFR) }\end{array}$} & \multicolumn{2}{|c|}{25 vs. 50 percentile } & \multicolumn{2}{|c|}{50 vs. 75 percentile } & \multicolumn{2}{|c|}{25 vs. 75 percentile } \\
\hline & Difference & $t$-value & Difference & $t$-value & Difference & $t$-value \\
\hline Income & -0.02 & $0.071 *$ & 0.01 & $0.076 *$ & -0.01 & $0.043 * *$ \\
\hline Unemp. rate & 0.02 & $0.031 * *$ & 0.007 & $0.032 * *$ & 0.027 & $0.008 * * *$ \\
\hline Pop. Density & -0.001 & $0.097 *$ & -0.011 & $0.042 * *$ & -0.012 & $0.071 *$ \\
\hline Under24 & 0.039 & $0.021 * *$ & 0.036 & 0.976 & 0.075 & $0.057 *$ \\
\hline Beer tax & -0.101 & $0.071 *$ & -0.06 & $0.002 * * *$ & -0.161 & $0.008 * * *$ \\
\hline Belt & 0.013 & $0.023 * *$ & -0.022 & $0.047 * *$ & -0.009 & $0.073 *$ \\
\hline ALR & -0.004 & $0.085 *$ & 0.011 & $0.058 *$ & 0.007 & $0.078 *$ \\
\hline Bac08 & 0.006 & $0.047 * *$ & 0.029 & 0.094 * & 0.035 & 0.046 * \\
\hline Zero Tolerance & 0.064 & $0.095 *$ & 0.035 & $0.012 * *$ & 0.099 & $0.023 * *$ \\
\hline MLDA & -0.001 & 0.057 * & -0.007 & $0.036 * *$ & -0.008 & $0.024 * *$ \\
\hline Speed limit & -0.016 & $0.049 *$ & -0.008 & $0.038 * *$ & -0.024 & $0.017 * *$ \\
\hline Open Container & 0.051 & $0.026 * *$ & -0.09 & $0.069 *$ & -0.039 & $0.053 *$ \\
\hline DUI fine & -0.028 & $0.051 *$ & 0.036 & $0.029 * *$ & 0.008 & $0.072 *$ \\
\hline North West & -0.009 & $0.052 *$ & 0.023 & $0.083 *$ & 0.014 & $0.045 * *$ \\
\hline Midwest & -0.016 & $0.066 *$ & 0.003 & $0.091 *$ & -0.013 & $0.057 *$ \\
\hline West & -0.027 & $0.043 * *$ & -0.078 & $0.000 * * *$ & -0.105 & $0.000 * * *$ \\
\hline Chow test & $0.046 * *$ & & $0.031 * *$ & & $0.026 * *$ & \\
\hline
\end{tabular}

Notes: 1. Each column presents the difference of coefficients between different quantile regressions; 2. $* * *, * *, *$ represent significance levels of $1 \%, 5 \%$, and $10 \%$, respectively; 3 . The differences in coefficients of state-specific time dummies and constants are not shown. 


\section{Discussion}

It is important for the relevant authorities to gain area-specific understanding of laws when amending them in order to save more lives from drinking and driving. Thus, we used the results from the empirical study on relevant policies to verify the arguments and discourse described above. Comparing the effects of all traffic laws in the three different quantiles, the most effective ones are the same for all three quantiles in the same order-zero tolerance, open container, and BAC. However, some laws are more effective in the areas with high alcohol-related fatalities, some are more effective in the areas with low alcohol-related fatalities, and others may not show consistent patterns across quantiles. In the areas with low alcohol-related fatalities, preventive regulations (beer tax, MLDA, and open container) may be more effective than ex-post regulations (such as BAC and zero tolerance), whereas ex-post regulations were more effective in areas with high fatalities, with an increase in effectiveness of $0.04 \%$ to $0.10 \%$ compared with their influence in the areas with low fatalities. Beer tax is most effective for the areas with low rate of alcohol fatalities but zero tolerance is most effective for the areas with high alcohol fatalities. DUI fine laws are effective for the areas with high alcohol fatalities but not so effective for the medium and low rates of alcohol fatalities.

These analyses show that the effectiveness of drinking and driving policies differed in areas with different rates of alcohol-related fatalities. Our results of all the policy effectiveness were statistically significant at $10 \%$ level or higher, except for DUI and speed limit in the areas with medium or high rates of alcohol-related fatalities. Even though the results were statistically significant in general, they might not imply social significance given the fact that the effectiveness (the magnitude of coefficients) of the laws was small. The law with greatest impact was zero tolerance, which decreased the rate of alcohol-related fatalities by $0.184 \%, 0.248 \%$, and $0.283 \%$ in the areas with low, medium, and high rates of alcohol-related fatalities, respectively (as shown in Table 2). However, these figures could be translated to $18.82,25.36$, and 28.94 lives saved, respectively, given that total 10,228 people were killed in alcohol-impaired driving crashes in 2012 (Dept of Transportation 2012). While this study did not intend to address the issue of social significance (To determine whether the results are socially significant, which can be referred to changes on measures that are important to society, some cut off points or thresholds need to be carefully defined [47,48], which is beyond the scope of this study.) and the implementation of each traffic law did not seem to save many lives, it is believed that each life counts and is of great importance to their family. Therefore, it is crucial for the relevant authorities to gain better understanding of traffic laws. When deciding on methods by which to lower alcohol-related fatalities, the U.S. states should consider the characteristics of drunk driving in their areas to effectively reduce fatality rates.

\section{Conclusions}

The statistics from the FARS of the NHTSA show that approximately 30,000 people were killed or injured in car crashes in the U.S. in 2009. Forty percent of these crashes occurred during weekends (approximately 12,000 casualties), possibly because people consume excessive quantities of alcohol at social engagements on weekends, causing severe alcohol-related crashes [37]. This indicates that 
drunk driving remains a severe social problem in the U.S. that motivates scholars and experts to identify factors that can reduce alcohol-related fatalities.

In this study, we used the alcohol-related fatalities per 100,000 people in the U.S. states between 1980 and 2009 for our analysis. The data show the following phenomena: (1) consistency: areas with high rates of alcohol-related fatalities in the 1980s remained so in 2009; and (2) regionality: areas with higher rates of alcohol-related fatalities were situated in the west and south, whereas areas with lower alcohol-related fatalities were situated in the northeast. These characteristics led us to question if drinking and driving policies had the same effects in areas with different rates of alcohol-related fatalities. Therefore, we used the QR method to discuss the effectiveness of various drinking and driving policies for different quantiles of alcohol-related fatalities.

The results from the empirical study show demographic factors such as income, unemployment rates, young driver ratio, and population density were all significant in areas with low rates of alcoholrelated fatalities; while only income and population density were significant in areas with high rates of alcohol-related fatalities. Considering the numbers of coefficients, we also find that lower beer tax and declined economic conditions (such as decreased income or increased unemployment) are correlated with higher rate of alcohol-related fatalities with impact greater in areas with low alcohol-related fatalities than in high fatality areas. Additionally, increased numbers of young drivers in areas with low rates of alcohol-related fatalities result in increased fatalities, whereas they did not significantly affect the fatalities in the areas with higher rates of alcohol-related fatalities. This implies that in areas with low alcohol-related fatalities (as compared to high fatality areas), drinking habits and attitudes may be restrained more easily by stricter drinking and driving policies and these areas are influenced to a greater extent by economic and demographic conditions. On the other hand, drinking habits and attitudes may not be easily changed in the areas with high alcohol-related fatalities; ex-post regulations are thus important for discouraging drinking people driving on the road. As a result, ex-post regulations are more important in the areas with high fatalities whereas preventive regulations are intended to prevent alcohol abuse and thus decrease alcohol-related fatalities in the areas with low fatalities.

\section{Conflicts of Interest}

The authors declare no conflict of interest.

\section{References}

1. Beck, K.H.; Kasperski, S.J.; Caldeira, K.M.; Vincent, K.B.; O’Grady, K.E.; Arria, A.M. Trends in Alcohol-related traffic risk behaviors among college students. Alcohol. Clin. Exp. Res. 2010, 34, 1472-1478.

2. Paschall, M.J. College attendance and risk-related driving behavior in a national sample of young adults. J. Stud. Alcohol 2003, 64, 43-49.

3. Phelps, C.E. Risk and perceived risk of drunk driving among young drivers. J. Policy Anal. Manag. 1987, 6, 708-714.

4. Whetten-Goldstein, K.; Sloan, F.; Stout, E.; Liang, L. Civil liability, criminal law, and other policies and alcohol-related motor vehicle fatalities in the United States: 1984-1995. Accid. Anal. Prev. 2000, 32, 723-733. 
5. Villaveces, A.; Cummings, P.; Koepsell, T.D.; Rivara, F.P.; Lumley, T.; Moffat, J. Association of alcohol-related laws with deaths due to motor vehicle and motorcycle crashes in the United States, 1980-1997. Am. J. Epidemiol. 2003, 157, 131-140.

6. Chang, K.; Wu, C.-C.; Ying, Y.H. The effectiveness of alcohol control policies on alcohol-related traffic fatalities in the United States. Accid. Anal. Prev. 2012, 45, 406-415.

7. Lovenheim, M.F.; Slemrod, J. The fatal toll of driving to drink: The effect of minimum legal drinking age evasion on traffic fatalities. J. Health Econ. 2010, 29, 62-77.

8. Hingson, R.; Heeren, T.; Winter, M.; Wechsler, H. Magnitude of alcohol-related mortality and morbidity among U.S. college students ages 18-24: Changes from 1998 to 2001. Annu. Rev. Public Health 2005, 26, 259-279.

9. Ruhm, C.J. Alcohol policies and highway vehicle fatalities. J. Health 1996, 15, 435-454.

10. Males, M.A. The minimum purchase age for alcohol and young-driver fatal crashes: A long term view. J. Leg. Stud. 1996, 15, 181-211.

11. Cook, P.J.; Tauchen, G. The effect of minimum drinking age legislation on youthful auto fatalities. J. Leg. Stud. 1984, 13, 169-190.

12. Saffer, H.; Grossman, M. Beer taxes, the legal drinking age, and youth motor vehicle fatalities. J. Leg. Stud. 1987, 16, 351-374.

13. Koenker, R.; Bassett, G.W. Regression quantiles. Econometrica 1978, 46, 33-50.

14. Koenker, R. Quantile regression for longitudinal data. J. Multivar. Anal. 2004, 91, 74-89.

15. Wagenaar, A.C. Effects of an increase in the legal minimum drinking age. J. Public Health Policy 1981, 2, 206-225.

16. Wilkinson, J.T. Reducing drunken driving: Which policies are most effective? South. Econ. J. 1987, 54, 322-334.

17. Wagenaar, A.C. Preventing highway crashes by raising the legal minimum age for drinking: The Michigan experience 6 years later. J. Saf. Res. 1986, 17, 101-109.

18. Dee, T.S. State alcohol policies, teen drinking and traffic fatalities. J. Public Econ. 1999, 72, 289315.

19. Voas, R.B.; Tippetts, A.S.; Fell, J. The United States limits drinking by youth under age 21: Does this reduce fatal crash involvements? Annu. Proc. Assoc. Adv. Automot. Med. 1999, 43, 265-278.

20. FellC, J.C.; Fisher, A.D.; Voas, B.R.; Blackman, K.; Tippetts, S.A. The relationship of 16 underage drinking laws to reductions in underage drinking drivers in fatal crashes in the United States.

Accid. Anal. Prev. 2008, 40, 1430-1440.

21. Hingson, R.; Heeren, T.; Winter, M. Lowering state legal blood alcohol limits to 0.08\%: The effect on fatal motor vehicle crashes. Am. J. Public Health 1996, 86, 1297-1299.

22. Fell, J.C.; Voas, R.B. The effectiveness of reducing illegal blood alcohol concentration (BAC) limits for driving: Evidence for lowering the limit to .05 BAC. J. Saf. Res. 2006, 37, 233-243.

23. Tippetts, A.S.; Voas, R.B.; Fell, J.C.; Nichols, J.L. A meta-analysis of .08 BAC laws in 19 jurisdictions in the United States. Accid. Anal. Prev. 2005, 37, 149-161.

24. Kaplan, S.; Prato, C.G. Impact of BAC limit reduction on different population segments: A Poisson fixed effect analysis. Accid. Anal. Prev. 2007, 39, 1146-1154. 
25. Wagenaar, A.C.; Maldonado-Molina, M.M.; Erickson, D.J.; Ma, L.; Tobler, A.L.; Komro, K.A. General deterrence effects of U.S. statutory DUI fine and jail penalties: Long-term follow-up in 32 states. Accid. Anal. Prev. 2007, 39, 982-994.

26. Zwerling, C.; Jones, M.P. Evaluation of the effectiveness of low blood alcohol concentration laws for younger drivers. Am. J. Prev. Med. 1999, 16, 76-80.

27. Wagenaar, A.C.; O’Malley, P.M.; LaFond, C. Lowered legal blood alcohol limits for young drivers: Effects on drinking, driving, and driving-after-drinking behaviors in 30 states. Am. J. Public Health 2001, 91, 801-804.

28. Voas, R.B.; Tippetts, A.S.; Fell, J.C. Assessing the effectiveness of minimum legal drinking age and zero tolerance laws in the United States. Accid. Anal. Prev. 2003, 35, 579-587.

29. Carpenter, C.S.; Kloska, D.D.; O’Malley, P.; Johnston, L. Alcohol control policies and youth alcohol consumption: Evidence from 28 years of monitoring the future. B. E. J. Econ. Anal. Pol. 2007, 7, 1-21.

30. Liang, L.; Huang, J. Go out or stay in? The effects of zero tolerance laws on alcohol use and drinking and driving patterns among college students. Health Econ. 2008, 17, 1261-1275.

31. Eisenberg, D. Evaluating the effectiveness of policies related to drunk driving. J. Policy Anal. Manag. 2003, 22, 249-274.

32. Voas, R.B.; Tippetts, A.S.; Fell, J. The relationship of alcohol safety laws to drinking drivers in fatal crashes. Accid. Anal. Prev. 2000, 32, 483-492.

33. Wagenaar, A.C.; Maldonado-Molina, M.M. Effects of drivers' license suspension policies on alcohol-related crash involvement: Long-term follow-up in forty-six states. Alcohol. Clin. Exp. Res. 2007, 31, 1399-1406.

34. Chaloupka, F.J.; Saffer, H.; Grossman, M. Alcohol control policies and motor vehicle fatalities. J. Leg. Stud. 1993, 22, 161-186.

35. Sloan, F.A.; Reilly, B.A.; Schenzler, C. Effects of prices, civil and criminal sanctions, and law enforcement on alcohol-related mortality. J. Stud. Alcohol 1994, 55, 454-465.

36. Young, D.J.; Likens, T.W. Alcohol regulation and auto fatalities. Int. Rev. Law Econ. 2000, 20, $107-126$.

37. Becker, G.S.; Posner, R.A. Uncommon Sense: Economic Insights, from Marriage to Terrorism; University of Chicago Press: Chicago, IL, USA, 2009.

38. Chaloupka, F.J.; Wechsler, H. Binge drinking in college: The impact of price, availability, and alcohol control policies. Contemp. Econ. Policy, 1996, 14, 112-124.

39. Phelps, C.E. Death and taxes: An opportunity for substitution. J. Health Econ. 1988, 7, 1-24.

40. Kenkel, D.S. Drinking, Driving, and Deterrence: The effectiveness and social costs of alternative policies. J. Law Econ. 1993, 36, 877-913.

41. Mann, R.E.; Zalcman, R.F.; Asbridge, M.; Suurvali, H.; Giesbrecht, N. Drinking-driving fatalities and consumption of beer, wine and spirits. Drug Alcohol Rev. 2006, 25, 321-325.

42. Sloan, F.A.; Githens, P.B. Drinking, driving, and the price of automobile insurance. J. Risk Insur. 1994, 61, 33-58.

43. Mast, B.D.; Benson, B.L.; Rasmussen, D.W. Beer taxation and alcohol-related traffic fatalities. South. Econ. J. 1999, 66, 214-249. 
44. Lamarche, C. Robust penalized quantile regression estimation for panel data. J. Econom. 2010, 157, 396-408.

45. Buchinsky, M. Estimating the asymptotic covariance matrix for quantile. J. Econom. 1995, 68, 303-338.

46. Leigh, J.P.; Waldon, H.M. Unemployment and highway fatalities. J. Health Polit. Policy Law 1991, 16, 135-156.

47. Kazdin, A.E. The meanings and measurement of clinical significance. J. Consult. Clin. Psychol. 1999, 67, 332-339.

48. Yates, B.T. Cost-effectiveness analysis, cost-benefit analysis and beyond: Evolving medels for the scientist-manager-practitioner. Clin. Psychol.: Sci. Pract. 1995, 2, 385-398.

\section{Appendix}

Table A1. Abbreviation of the states in the USA (by alphabetic order).

\begin{tabular}{lclc}
\hline \multicolumn{1}{c}{ State } & Abbreviation & \multicolumn{1}{c}{ State } & Abbreviation \\
\hline Alabama & AL & Montana & MT \\
Alaska & AK & Nebraska & NE \\
Arizona & AZ & Nevada & NV \\
Arkansas & AR & New Hampshire & NH \\
California & CA & New Jersey & NJ \\
Colorado & CO & New Mexico & NM \\
Connecticut & CT & New York & NY \\
Delaware & DE & North Carolina & NC \\
Florida & FL & North Dakota & ND \\
Georgia & GA & Ohio & OH \\
Hawaii & HI & Oklahoma & OK \\
Idaho & ID & Oregon & OR \\
Illinois & IL & Pennsylvania & PA \\
Indiana & IN & Rhode Island & RI \\
Iowa & IA & South Carolina & SC \\
Kansas & KS & South Dakota & SD \\
Kentucky & KY & Tennessee & TN \\
Louisiana & LA & Texas & TX \\
Maine & ME & Utah & UT \\
Maryland & MD & Virginia & VA \\
Massachusetts & MA & Vermont & VT \\
Michigan & MI & Washington & WA \\
Minnesota & MN & West Virginia & WV \\
Mississippi & MS & Wisconsin & WI \\
Missouri & MO & Wyoming & WY \\
\hline
\end{tabular}

(C) 2013 by the authors; licensee MDPI, Basel, Switzerland. This article is an open access article distributed under the terms and conditions of the Creative Commons Attribution license (http://creativecommons.org/licenses/by/3.0/). 